\title{
CORRESPONDENCE
}

\section{Nitrites in Trouble}

SIR,--In the recent report by your Washington Correspondent (Nature, 239,$63 ; 1972$ ) on the current arguments concerning the permissibility of nitrite as a food additive in the USA, there are several misrepresentations of fact which we feel should be clarified. Further, the opinions expressed in some of the statements have not been adequately substantiated in our opinion by experimental results.

The contention that nitrite is permitted as a curing agent but not as a preservative is a non sequitur since by definition the act of curing is a form of preservation ("cure": preserve (meat, fruit, tobacco) by salting, drying and so on-Concise Oxford Dictionary). Thus the role of nitrite is not only as a precursor in pigment production but also in development of the typical flavours of cured meat ${ }^{1}$ and in microbiological stability. In particular, nitrite may be essential for the inhibition of germination and outgrowth of spores of Clostridium botulinum. The statement that "there is considerable doubt about the viability of some cured meats as a culture medium for the spores" is surely without foundation. Concentrations of sodium chloride which when used alone are necessary to inhibit the growth from spores of $\mathrm{Cl}$. botulinum, range from 4 to $5 \%$ for type $\mathrm{E}$ and from 8 to $10 \%$ for types $\mathrm{A}$ and $\mathrm{B}$. With modern consumer requirements for low salt bacon and meat products, on purely organoleptic grounds, the level of sodium chloride normally used in cured meats ranges normally from $3.5 \%$ to $5 \%$ on the aqueous phase. In such products, toxin production by $\mathrm{Cl}$. botulinum can occur unless adequate nitrite is present also in the product. The amount of nitrite required to inhibit germination and outgrowth of the spores is dependent upon many factors including the $p \mathrm{H}$ value, the salt content and the degree of heat process (in the case of canned hams) which is given to the product. It is also dependent upon the number and type of spores of $\mathrm{Cl}$. botulinum present ${ }^{2}$. The microbiological stability of pasteurized cured meats may also be influenced by the production of an as yet unidentified antimicrobial agent developed from nitrite $^{3}$

The statement that meat was involved in only one case of botulism (sic in the USA?) during the period 1950 to 1963 is probably correct. It should be recorded also that no outbreaks of botulism caused by consumption of cured meat products have been recorded in the UK during the present century. However, in France there were sixty-six outbreaks of botulism affecting some 131 persons during the period 1956-1970". Of these, the majority were attributed to consumption of home-cured ham. It is pertinent to note that residual nitrite was not detected in some of the French hams examined (M. Sebald, personal communication, 1971).

Furthermore, in his assessment of the reported controversy over the potential nitrosation in the stomach of secondary amines of dietary or other origin, your correspondent has failed to recognize the paramount importance of the structure of the amine to the outcome. For instance, Dr Mirvish ${ }^{5}$ of the Eppley Institute, University of Nebraska, has found a 185,000 -fold difference in the rates of nitrosation under optimal conditions between the weakly basic piperazine and the strongly basic piperidine. This is reflected in the lack of tumour formation after concurrent feeding of nitrite with a strongly basic amine such as dimethylamine ${ }^{6}$. Whether or not the amines present in foodstuffs or administered as drugs do actually nitrosate in the stomach with the low levels of nitrite available in foodstuffs or present normally in the saliva of the individual must await the outcome of current research, taking account of other reactions competing for the available nitrite.

Naturally your Washington correspondent has dealt exclusively with research, opinions and legislation in the western hemisphere. In so doing, he has had no opportunity to include the extensive programme of research on the role of nitrite in the preservation of meat proceeding at this and other laboratories in the UK and other European countries, particularly Germany.

Yours faithfully,

B. JARVIS

C. L. Walters

The British Food Manufacturing

Industries Research Association,

Randalls Road,

Leatherhead,

Surrey

${ }^{1}$ Cho, I. C., and Bratzler, L. J., J. Food Sci., 35, 668 (1970).

2 Roberts, T. A., et al., Ann. Rpt. Meat Research Inst., 1970-71, 77 (1972).

${ }^{3}$ Ashrorth, J., and Spencer, R., J. Fd. Technol., 7, 111 (1972).

${ }^{4}$ Sebald, M., Bull. Acad. Nat. Med., 154, 26 (1970)
${ }^{5}$ Mirvish, S. S., Proc. Joint Meeting on the Analysis and Formation of Nitrosamines organized by the International Agency for Research on Cancer, Lyon, and Deutsches Krebsforschungszentrum, Heidelberg (1971).

- Greenblatt, M., Mirvish, S. S., and So, B. T., J. Nat. Cancer Inst., 46, 1029 (1971).

Our Washington Corerspondent replies :

1. The authors question the distinction between the use of nitrite to fix colour in the curing of meats, and its use as a preservative. They point out that curing implies preservation. Clearly, however, the possible distinction is extremely important in the United States because it is being used by the Center for the Study of Responsive Law and others as a central part of their motion for summary judgment in their suit against the Department of Agriculture. The situation is essentially as follows. The 1958 amendments to the Food and Drug Laws provided exemption for those food additives which are "used in accordance with a sanction or approval granted prior to September 6, 1958, pursuant to the Meat Inspection Act of 1907'. This so-called grandfather clause means that such food additives need not go through the stringent testing and review prescribed by the 1958 amendments. The law suit, however, contends that in the 1920s the Department of Agriculture allowed nitrite to be used in the curing of meat "to fix color", and not to prevent the growth of $\mathrm{Cl}$. botulinum. The Department of Agriculture, in its own motion for summary judgment in the case brought by the Center for the Study of Responsive Law, defended use of nitrite largely on the grounds that it prevents growth of $\mathrm{Cl}$. botulinum and its toxin. The plaintiffs are therefore claiming that the USDA is defending the additive for a use which has not been sanctioned and which does not come under the grandfather clause. Their contention is that the USDA can only defend use of nitrite as a colour fixer because that is the only sanctioned use in curing meats. (The Food and Drug Administration has, however, approved use of nitrite as a preservative in the curing of chub fish, but this action was taken after the 1958 amendments and is not part of the argument here.) I maintain therefore that the contention is not necessarily a non sequitur, and it is up to the courts to decide. It is an important issue in the case. 